\title{
Natural Hazards
}

\section{Seismic Risk in the city of Al Hoceima (North of Morocco) using the Vulnerability Index Method, applied in Risk-UE project \\ --Manuscript Draft--}

\begin{tabular}{|c|c|}
\hline Manuscript Number: & NHAZ-D-15-00798R1 \\
\hline Full Title: & $\begin{array}{l}\text { Seismic Risk in the city of Al Hoceima (North of Morocco) using the Vulnerability Index } \\
\text { Method, applied in Risk-UE project }\end{array}$ \\
\hline Article Type: & Manuscript \\
\hline Keywords: & seismic vulnerability; seismic risk; Al Hoceima; Risk-UE \\
\hline Corresponding Author: & $\begin{array}{l}\text { Seif-eddine CHERIF, M.D. } \\
\text { Mohammed First University } \\
\text { Oujda, Oriental MOROCCO }\end{array}$ \\
\hline \multicolumn{2}{|l|}{$\begin{array}{l}\text { Corresponding Author Secondary } \\
\text { Information: }\end{array}$} \\
\hline Corresponding Author's Institution: & Mohammed First University \\
\hline \multicolumn{2}{|l|}{$\begin{array}{l}\text { Corresponding Author's Secondary } \\
\text { Institution: }\end{array}$} \\
\hline First Author: & Seif-eddine CHERIF, M.D. \\
\hline \multicolumn{2}{|l|}{ First Author Secondary Information: } \\
\hline \multirow[t]{4}{*}{ Order of Authors: } & Seif-eddine CHERIF, M.D. \\
\hline & Mimoun CHOURAK, PhD \\
\hline & Mohamed ABED, PhD \\
\hline & Luis PUJADES, PhD \\
\hline \multicolumn{2}{|c|}{ Order of Authors Secondary Information: } \\
\hline \multicolumn{2}{|l|}{ Funding Information: } \\
\hline Abstract: & $\begin{array}{l}\text { Al Hoceima is one of the most seismic active regions in north of Morocco. It is } \\
\text { demonstrated by the large seismic episodes reported in seismic catalogs and research } \\
\text { studies. However, seismic risk is relatively high due to vulnerable buildings that are } \\
\text { either old or don't respect seismic standards. Our aim is to present a study about } \\
\text { seismic risk and seismic scenarios for the city of Al Hoceima. The seismic vulnerability } \\
\text { of the existing residential buildings was evaluated using the Vulnerability Index Method } \\
\text { (Risk-UE). It was chosen to be adapted and applied to the Moroccan constructions for } \\
\text { its practicality and simple methodology. A visual inspection of } 1.102 \text { buildings was } \\
\text { carried out to assess the vulnerability factors. As for seismic hazard, it was evaluated } \\
\text { in terms of macroseismic intensity for two scenarios (a deterministic and probabilistic } \\
\text { scenario). The maps of seismic risk are represented by direct damage on buildings, } \\
\text { damage to population and economic cost. According to the results, the main } \\
\text { vulnerability index of the city is equal to } 0.49 \text {, and the seismic risk is estimated as slight } \\
\text { (main damage grade equal to } 0.9 \text { for the deterministic scenario and } 0.7 \text { for the } \\
\text { probabilistic scenario). However, moderate to heavy damage is expected in areas } \\
\text { located in the newer extensions, both in the east and west of the city. Important } \\
\text { economic losses and damage to the population are expected in these areas as well. } \\
\text { The maps elaborated can be a potential guide to the decision making in the field of } \\
\text { seismic risk prevention and mitigation strategies in Al Hoceima. }\end{array}$ \\
\hline Response to Reviewers: & $\begin{array}{l}\text { Reviewer \#1: } \\
\text { In order to increase the quality of the manuscript } \\
\text { 1)The abstract states that: "..an adaptation of the vulnerability index method proposed } \\
\text { by Risk-UE project is made". Therefore, could you explain what is this adaptation?. } \\
\text { Perhaps by regional modifier?. According line } 144 \text {, the regional modifier takes into } \\
\text { account the characteristics of the region or the period of construction of the building. }\end{array}$ \\
\hline
\end{tabular}


What is the value of regional modifier in this study? if according to the construction period, it should be specified which has been the approach taken for setting periods of construction before 1960, between 1961 and after 1994 and 1995 (paragraph beginning at line 69). Whether they are the same periods that the Riskue project or there is a specific regulation, or other reason for setting those periods.

The regional modifier is been taken equal to zero (it's been added in line 177). The adaptation was more focused on defining the characteristic construction periods for the city and determining the building typologies. This time, it's been explained clearly (line 82).

2)In legend of Figure3b: Could you explain what "poorly, moderately and well-studied area" mean? Maybe, you could assign each class a percentage or a range of buildings or area studied...

Figure 3b's legend has been replaced by the percentage of the studied buildings for each section.

3)Nor it is clearly reflected validation of the results for the deterministic scenario . As only mentioned in passing and in a qualitative way (no casualties and slight damage in line 332) referring to Goula and Gonzalez (2004). But you have specific data of the 2004 earthquake survey reports (with 629 fatalities, 966 injuries and 15600 homeless in line 37-39).

The specific data from survey reports (with 629 fatalities, 966 injuries and 15600 homeless in line 41-43) was for the whole region of northern Morocco. Actually, most damage was observed in rural areas. However, rural housing was not considered in the study due to lack of information (number and distribution of inhabitants + lack of statistics). Moreover, these precarious dwellings (that don't respect construction standards) are regarded as illegal since 2004 by the administration and are being replaced with others meeting the construction standards.

As for the city of Al Hoceima, there was no collapse or heavy damage. Only fractures of 2 nd degree (Moderate damage) were observed in some buildings of $\mathrm{C}$ class (VI ranging from 0.5 to 0.7 ) in $\mathrm{Al}$ Manzah district.

Minor revision:

4)Line 281. Why table 4 shows values of loss indices for AUTh, IZIIS and UNIGE, if only Aristotle University's values are taken into account in the study?

The table was corrected showing only loss indices for (AUTh) (now table 6 line 359)

5)line 62: explain the meaning of "R.C.".

"R.C." has been replaced by "reinforced concrete"

6)line 70,79 and figure 5 , terms storeys and floors should be unified

The terms now are unified using "floors" (lines 82 and figure 5)

7)Regarding the bibliographic references:

More recent references have been added.

"EMS98 1998)" has been replaced by the author (Grünthal 1998) (line 162)

"(Geological Service of Morocco, 1984)" has been replaced by the authors "Choubert and Faure-Muret 1984" (line 129) and added to the references.

The style of the references has been homogenized. However, according to the instructions for authors, in case of two authors, the expression in the citation is different than the one in the reference list.

Reference "Le Haut Commissariat Au Plan statistiques" has been replaced by the census that took place, and added to the reference list (lines 38, 81, 320)

References related to the "R.P.S.2000" have been classified according to their version (lines 24, 92, 119) and added to the reference list 
Reviewer \#2:

General comments:

1)The abstract should be reviewed. More results should be included in abstract. The last paragraph: "these maps also constitute valuable information for urban planning and development of the city" could be removed because seismic hazard is roughly analysed in the work.

The abstract has been reviewed and restructured according to the mentioned instructions; more results have been added and the mentioned sentence has been removed.

2)The geotechnical data of the urban area used don't appear in the manuscript. The criteria for soil classification must be specified better.

The part about soil effects has been redone. A lithological map has been added. The criteria for soil classification has been explained further (122-155)

3)In the line 217 is indicated "soil effects don't have a strong amplifying impact on the buildings in case of an earthquake" but in in figure 6 soils type $B$ and $C$ are shown and an increment in intensity of 0.5 degrees was proposed to construct the intensity map with soil effects (line 117).

The sentence "soil effects don't have a strong amplifying impact on the buildings in case of an earthquake" has been replaced by "since soil effect is present in small areas of the city (equivalent of $7 \%$ of the total surface)" (line 267)

The areas with soil $B$ and $C$ constitute only $7 \%$ of the total surface of the city.

4)The building types should be described better and must be correlated with those of Risk-UE Building Typology Matrix.

The buildings have been described better and correlated with the BTM. More results have been added to the seismic vulnerability section. (Line 226-267)

\section{Specific Comments:}

5)Line 3: is generally considered as a moderate seismic zone (include reference or specify the expected maximum ground motion).)

References have been included (line 3)

6)Line 35: Check the following: this leads to an average density of 13,770 inhabitants per square meter and an average of 4.9 inhabitants per building. There is a great inconsistency between both statements.

The sentence has been corrected. (Line 39)

7)Line 35: struck a part of the city. Damage was observed in a part of the city but only a part was struck?

The sentence has been corrected (line 41)

8)Line42: Complete the legend of this figure.

The legend of the figure has been completed (line52)

9)Line 50: In Figure 3 (a) is not specified the limit of each district or quarter nor the meaning of the colors.

The limits of districts have been added, and the variation of colors has been removed. (line 56)

10)Line 61: Change shanty towns, I think is too pejorative. These quarter are built without urban planning and the building are irregular RC frame, as you say, then they can be described as: poor neighborhoods with carelessly built constructions or so.

The sentence has been changed to "poor neighborhoods with carelessly built 
constructions" (line 68)

11)Line 64: are generally of the same kind type.

The sentence has been corrected. (Line 72)

12)Line 71: Why don't consider the Seismic Regulations of Morocco RPS2000?. Don't had new regulations?. Don't was applied?. And after 2011 ?.

The design and construction requirements part from the RPS2000 has been applied in the city before the 2000s. After the 1994 earthquake in Al Hoceima, building design and construction required an immediate solution. Based on expert judgment and other standards (PS92 and BAEL), decision have been made to better the seismic protection, and have been applied immediately in the city, but were added subsequently to the RPS2000 (2002) for a national coverage. The decision made for defining code levels is now better explained (Line 82)

13)Line 105: Geological Service of Morocco, 1984 is not included in reference list.

"Geological Service of Morocco, 1984" citation has been replaced by its authors "Choubert and Faure-Muret 1984" (line 129) and added to the reference list.

14)Line 206: No details about vulnerability are presented. Why?. What is the main vulnerability factors that were assessed and their values?, what type of buildings change their final vulnerability index?, what were the causes?.

The seismic vulnerability of the city has been given its own part. More details about the results have been added and more comments on the importance of behavior modifiers have been added (Line 226-267)

15)Line 217: It should be emphasized that Figure 9 shows mean damage index for two seismic hazard scenarios and for this reason no large differences are appreciated between both. Additionally, it would be discussed that heavy and destruction damage there could be in areas with DSm>1.5.

The comment has been added in line 269. Additionally, figures showing the probability of damage for each district had been added to highlight the possibility of heavy damage or collapse in some of the districts (figure 12 and 13).

16)Line 254: No details appear in the manuscript about the number of persons who are assumed to live in each household of the building in Al hoceima city.

A reference has been added for the number of persons per household (which is equal to 5 ) in line 321. 


\title{
Seismic Risk in the city of Al Hoceima (north of Morocco) using the Vulnerability Index Method, applied in Risk-UE project
}

\author{
Seif-eddine Cherif $\bullet$ Mimoun Chourak $\bullet$ Mohamed Abed $\bullet$ Luis Pujades
}

\begin{abstract}
$\mathrm{Al}$ Hoceima is one of the most seismic active regions in north of Morocco. It is demonstrated by the large seismic episodes reported in seismic catalogs and research studies. However, seismic risk is relatively high due to vulnerable buildings that are either old or don't respect seismic standards. Our aim is to present a study about seismic risk and seismic scenarios for the city of Al Hoceima. The seismic vulnerability of the existing residential buildings was evaluated using the Vulnerability Index Method (Risk-UE). It was chosen to be adapted and applied to the Moroccan constructions for its practicality and simple methodology. A visual inspection of 1.102 buildings was carried out to assess the vulnerability factors. As for seismic hazard, it was evaluated in terms of macroseismic intensity for two scenarios (a deterministic and probabilistic scenario). The maps of seismic risk are represented by direct damage on buildings, damage to population and economic cost. According to the results, the main vulnerability index of the city is equal to 0.49 , and the seismic risk is estimated as slight (main damage grade equal to 0.9 for the deterministic scenario and 0.7 for the probabilistic scenario). However, moderate to heavy damage is expected in areas located in the newer extensions, both in the east and west of the city. Important economic losses and damage to the population are expected in these areas as well. The maps elaborated can be a potential guide to the decision making in the field of seismic risk prevention and mitigation strategies in Al Hoceima.
\end{abstract}

Keywords: Seismic vulnerability $\bullet$ Seismic risk $・$ Al Hoceima $・$ Risk-UE

Acknowledgements This research benefited from the ICTP-OEA (Trieste) Programme in the framework of the North African Group for Earthquake and Tsunami studies (NAGET) activities. We also thank two anonymous reviewers' valuable comments which helped to improve this paper

\section{Introduction}

The Rif region, in north of Morocco, is generally considered as a moderate seismic zone (Poujol et al. 2014). It is also recognized as the most seismically active part of Morocco (Cherkaoui et al. 1990; El Alami et al. 1998; Bezzeghoud and Buforn 1999), its high level of seismicity makes it one of the most studied active zones in the western Mediterranean (d'Acremont et al. 2014; Tahayt 2009). It has experienced several earthquakes, some of them very destructive, as in the case of $1994\left(M_{W}=6.0\right)$ and $2004\left(M_{W}=6.4\right)$ earthquakes (Woerd et al. 2014). Also, very recently, a 6.3 magnitude earthquake

S.Cherif

Département de Géologie, Faculté des Sciences, Université Mohammed Premier

BP 71760000 Oujda Maroc

e-mail : seif.cherif.00@gmail.com

telephone : +212699929208

M.Chourak

Ecole Nationale des Sciences Appliquées Oujda, Université Mohammed Premier

BP 669, Oujda 60000, Maroc

M.Abed

Université de Blida, Algérie

Route de Soumâa, BP 270, Blida 09000, Algérie

L.Pujades

Department of Geotechnical Engineering and Geosciences, Civil Engineering School, Technical

University of Catalonia, Edificio D2, Campus Norte UPC, Jordi Girona 1-3, 08034 Barcelona, Spain 
struck $50 \mathrm{Km}$ from Al Hoceima early on Monday January $26^{\text {th }} 2016$ (USGS), causing some material damage. This seismicity is due to the convergence between the Eurasian and African plates (Casado et al. 2014). Despite the relatively moderate activity in the north, some of its existing buildings have a high degree of vulnerability. Therefore, a significant probability of damage can be expected even in the case of not excessively severe earthquakes. Since the 2004 earthquake, seismologists became more interested in seismic hazard in the region (Ait Brahim et al. 2004; Mourabit et al. 2013). However, the same cannot be said about seismic vulnerability, which is a relatively new field, to what it hasn't been given the proper attention it deserves, hence the importance of this study.

The Vulnerability Index Method (VIM) was used to assess the seismic vulnerability. The method was a part of the Risk-UE project; it has been applied to assess the seismic risk for seven European cities (Barcelona, Bitola, Bucharest, Catania, Nice, Sofia and Thessaloniki) (Mouroux et al. 2004; Pitilakis et al. 2006; Lantada et al. 2010) around the Mediterranean Sea. The choice for this assessing technique is motivated by its simplified methodology which allows considering numerous uncertainties. In fact, it defines the seismic action in terms of macroseismic intensity, the seismic resistance of buildings in terms of a vulnerability index, and it considers five non-null damage states. Moreover, both the deterministic and probabilistic scenarios have been considered, including soil effects. The deterministic scenario refers to the 2004 earthquake that struck the northern region of Morocco as a reference earthquake while the probabilistic scenario has a probability of exceedance of $10 \%$ in 50 years (R.P.S. 2000, Version 2011).

The goal of our study is to elaborate seismic risk maps, based on the seismic hazard assessment in terms of intensity and defined by both scenarios and the seismic vulnerability of the studied buildings. The seismic risk is represented by the distribution of the expected damage grade in the city, as well as the estimated number of homeless people and the economic losses in each area of Al Hoceima (Fig. 1).

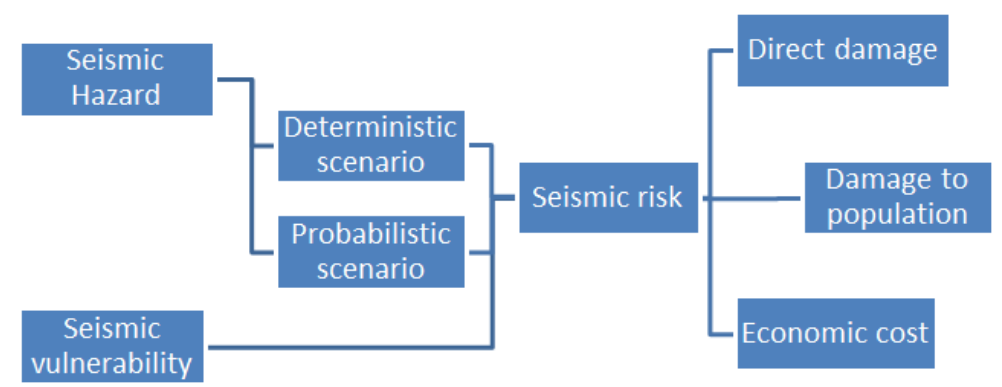

Fig. 1 Methodology adopted for the seismic risk assessment in the city of Al Hoceima

\section{The city of Al Hoceima}

The city of Al Hoceima is located in the Rif Mountains, northeast of Morocco (Mediterranean Sea) (Fig. 2) with a terrain characterized by a slope going from $10 \%$ to $40 \%$. According to the official statistics of 2014 (RGPH 2014), the city counts 56.666 citizens (13.770 inhabitants per square kilometer) and 11.554 residential buildings. It is also worth mentioning that the population of the city triples in the summer. It's on the night of February 24th, 2004, an earthquake, 6.4 of moment magnitude struck the city and the surrounding communities (Woerd et al. 2014), causing 629 fatalities, 966 injuries, 2539 destroyed and damaged houses and 15.600 homeless (Tahayt et al. 2009). Most damage was observed in rural areas (Faradi 2004; Corella 2004; Poujol et al. 2004; Goula and Gonzalez 2004).

For the purposes of this study, the city was subdivided into sections according to several factors; for instance, district limits, building classes (residential, commercial, etc.) and other factors of building construction (Fig. 3a). Each section is represented by a pattern of buildings which typifies the main similar characteristics of the construction area. Due to limited 
resources, some areas have been focused on more than others. The priority has been given to the downtown area, since it is the most populated. Figure $3 \mathrm{~b}$ shows the study level of each section represented by the percentage of the studied buildings.
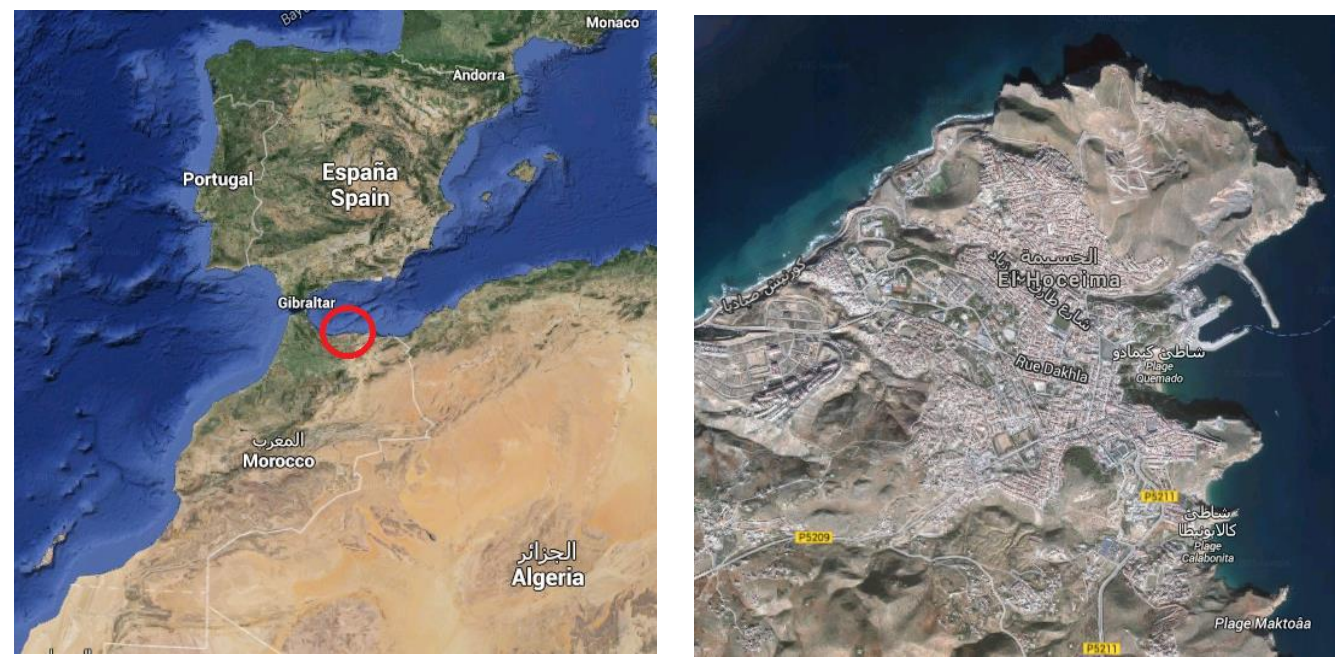

Fig. 2 a Landsat satellite image of western Mediterranean (Google Earth) and location of the city of Al Hoceima. b Plan view of satellite image (Google Earth) of the Al Hoceima cape
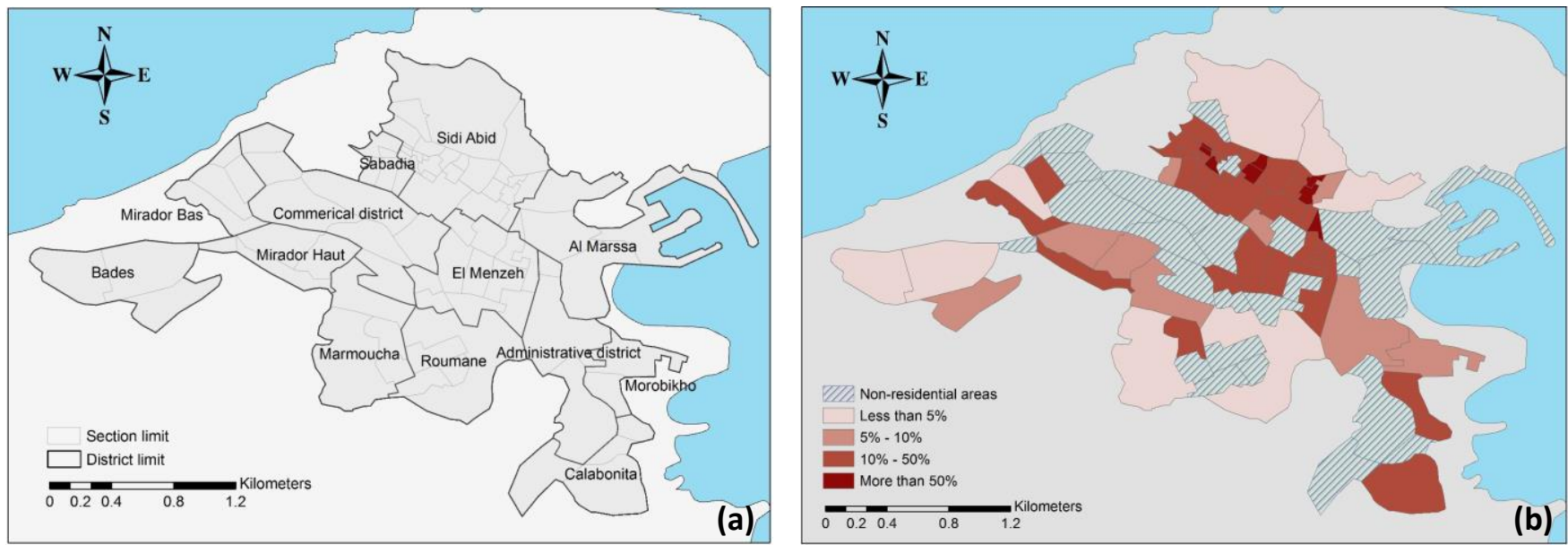

Fig. 3 a Administrative districts and subdivision of Al Hoceima. b Study level of the areas represented by the percentage of the studied buildings in Al Hoceima

\section{Residential buildings}

$\mathrm{Al}$ Hoceima is a newly established city (20th century); this is justified by the absence of a Medina (an old downtown) and the fact that most of the buildings are reinforced concrete structures. As most cities, Al Hoceima has a city center surrounded by residential districts. The city center is relatively the oldest quarter in the city and its buildings aren't similar, since there are many reconstruction sites in these areas. In fact, many new buildings designed with the latest seismic code standards are situated close to old constructions lacking the basic standards of construction. Extensions were built after 2004 in the southeastern and western part of the city, for instance Bades, which is the newest neighborhood destined for tourism, and the southern part of the Mirador Bas and Mirador Haut districts, which can be described as poor neighborhoods with carelessly built constructions (Fig. 4). For these two neighbourhoods, it can be noted that reinforced concrete irregular frames constitute mainly the framework of encountered constructions; a steep slope characterizes the ground and, finally, the absence of 
respect to the current construction rules. Unlike the city center, the buildings in the new neighborhoods are generally of the same type.
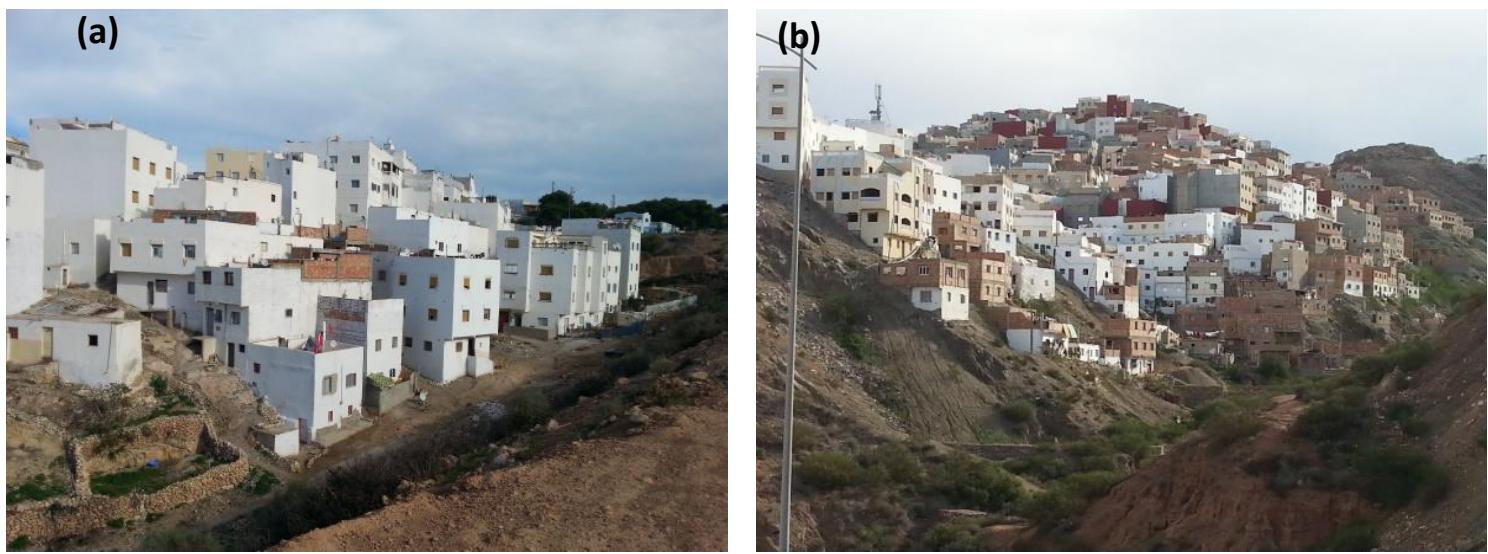

Fig. 4 a Buildings in Mirador Bas neighborhood. b Buildings in the Mirador Haut quarter
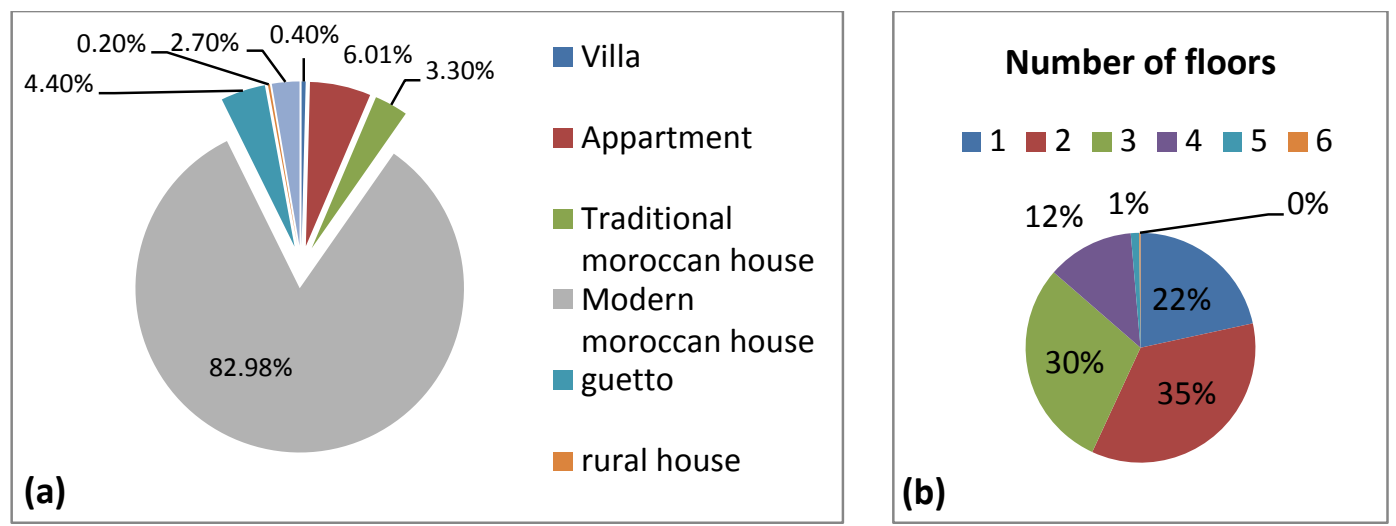

Fig. 5 a Building distribution according to their types, as stated in the official statistics of the city in 2004 (RGPH 2004). b Distribution of the number of floors by building according to the studied 1102 buildings

One type of housing prevails in the city, and it is the modern Moroccan house (RGPH 2004). The latter is often a reinforced concrete structure with two to three floors (Fig. 5). Construction standards in the Rif region have experienced changes depending on 2 major events:

1. The 1960 earthquake in Agadir: The night of February 29th, 1960, Agadir had experienced one of the world's most destructive earthquakes in the 20th Century (Coburn and Spence 2002). The studies and investigations in site led to elaborate the first seismic standard, namely "Agadir Standard". However, without a proper seismic code, Moroccan construction has been greatly affected by this standard.

2. The 1994 earthquake in $\mathrm{Al}$ Hoceima: A violent earthquake $\left(\mathrm{M}_{\mathrm{w}}=6.0\right)$ struck the region of Al Hoceima killing three people and causing extensive damage (Akoglu et al. 2006; RMSI 2012). After the earthquake, constructive measures have been taken to protect buildings in the Rif region; they were inspired by the PS92 and BAEL 91. These decisions were applied after 1994 in the area and, subsequently, contributed in elaborating the first national seismic code R.P.S.2000.

Thus, three code levels have been defined following the construction periods (Table 1).

Table 1 Adopted code level for existing buildings in Al Hoceima

\begin{tabular}{|l|c|c|c|}
\hline Construction period & Pre 1960 & $1960-1994$ & Post 1994 \\
\hline Code level & Low code & Medium code & High code \\
\hline
\end{tabular}


The direct relation between the period of construction and the code level is valid for most districts except for Mirador Bas and Mirador Haut, since the two neighborhoods have been recently built (after 2004) but don't respect the latest codes of construction. The data collected represents 1.102 buildings, which is around $10 \%$ of the total households in the city. The information gathered is centered on the geometry and the structural nature of the buildings as well as the location of the unit compared to the adjacent buildings.

102

103

104

105

106

107

108

109

110

111

112

113

114

115

116

117

118

119

120

121

122

123

124

125

126

127

\section{Seismic action assessment in terms of intensity for Al Hoceima}

\subsection{Deterministic and probabilistic scenarios}

In this study, the seismic action has been estimated in terms of macroseismic intensity using a deterministic and a probabilistic scenario. Given the small size of the city, the macroseismic intensity at the basement is considered to be constant all over the city for both scenarios. The deterministic scenario refers to a reference earthquake chosen as the closest one to the site with the highest epicentral intensity. In this case, the reference earthquake is the one that struck the city in February $24^{\text {th }}, 2004$ with an epicentral intensity of IX and the expected intensity for the city of Al Hoceima is VIII (Cherkaoui and El Hassani 2012). The event occurred at an epicentral distance less than 10km from the city and has been assigned a depth between 6 and $10 \mathrm{~km}$ (Woerd et al. 2014).

The probabilistic seismic hazard in terms of intensity has been addressed before by the RMSI (Risk Management Solutions Inc.) in 2012. According to the results, the city of Al Hoceima is expected to be affected by an intensity of VII-VIII and an equivalent peak ground acceleration of $0.253 \mathrm{~g}$ for a return period of 475 years (a probability of exceedance of $10 \%$ in 50 years). According to the Seismic Regulations of Morocco (R.P.S. 2000, Version 2011) the expected acceleration for a return period of 475 is $0.18 \mathrm{~g}$ which is inferior to the one estimated by the RMSI report.

\subsection{Seismic scenarios with soil effects}

Several approaches are used for the assessment of soil effects. A good method would be to construct a site dependent scenario ground motion map and to identify zones prone to seismically induced slope failure and liquefaction. To this end, a suitable geotechnical zonation of the urban area is needed (Faccioli 2006).
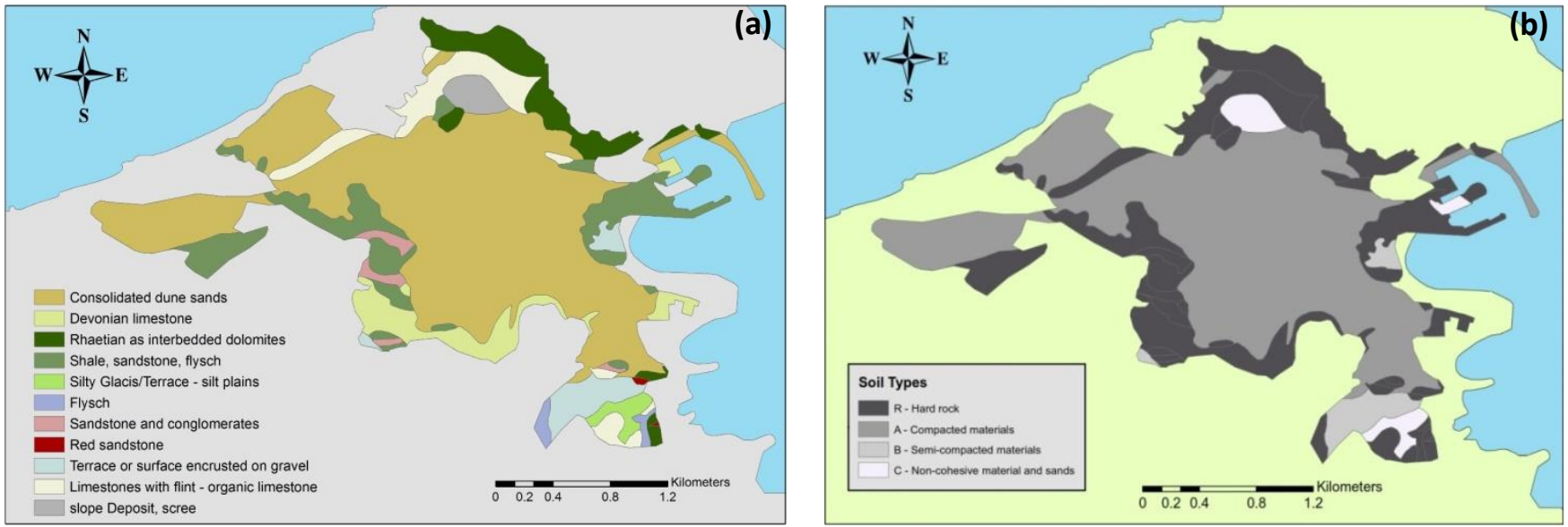

Fig. 6 a Lithological map of Al Hoceima (Choubert and Faure-Muret 1984 modified). b Distribution of soil types in the city of Al Hoceima 
Due to the lack of geotechnical data on the region, a lithological map was used (Fig. 6a). The study area is situated within the eastern part of the Rif intermountain belt and is dominated by geological formations of the inner domain characterized by carbonated rocks (calcareous and dolomites), these are overlain in part by Paleozoic terrains (Ghomarides) (Talhaoui et al. 2004). Based on the analysis of surface geological formations, a map of different types of soils was compiled (Fig. 6b). The sites were classified in four main categories, zone A, B and C corresponding respectively to: compacted materials, semicompacted materials and non-cohesive materials in addition to Hard rock (R) (Table 1).

The intensity is implemented depending on the type of soil. The increments are calculated by empirical methods (Secanell 1999; Bard 1997). This way for introducing soil effects in terms of intensity was also recommended within the Risk-UE project (Faccioli 2006) in case geotechnical data in not available. For soil types $\mathrm{R}$ and A, no increment in intensity is applied, while for soil types B and C an increment in intensity of 0.5 degrees was applied to construct the intensity map with soil effects.

Table 1 Site classification for the city of Al Hoceima

\begin{tabular}{|l|l|l|}
\hline Zones & Sites & Increments (Intensity) \\
\hline A - Compacted materials & Consolidated dune sands & +0.0 \\
\hline B - Semi-compacted materials & Terrace or surface encrusted on gravel, & +0.5 \\
\hline C - Non-cohesive materials & Slope Deposit, scree, Silty Glacis/Terrace - silt plains & +0.5 \\
\hline R - Hard Rock & Limestone, flysch, sandstone, dolomites, shale & +0.0 \\
\hline
\end{tabular}

Figure 7a shows the map for deterministic seismic hazard with soil effects in terms of intensity for the city of Al Hoceima, while Figure $7 \mathrm{~b}$ presents the map for the probabilistic seismic hazard for a return period of 475 years including soil effects for the city of Al Hoceima. As can be seen from the figures the deterministic scenario's intensity is slightly higher than the one expected from the probabilistic scenario. As for the terrain affected by soil effect, it represents only $7 \%$ of the total surface of the city.
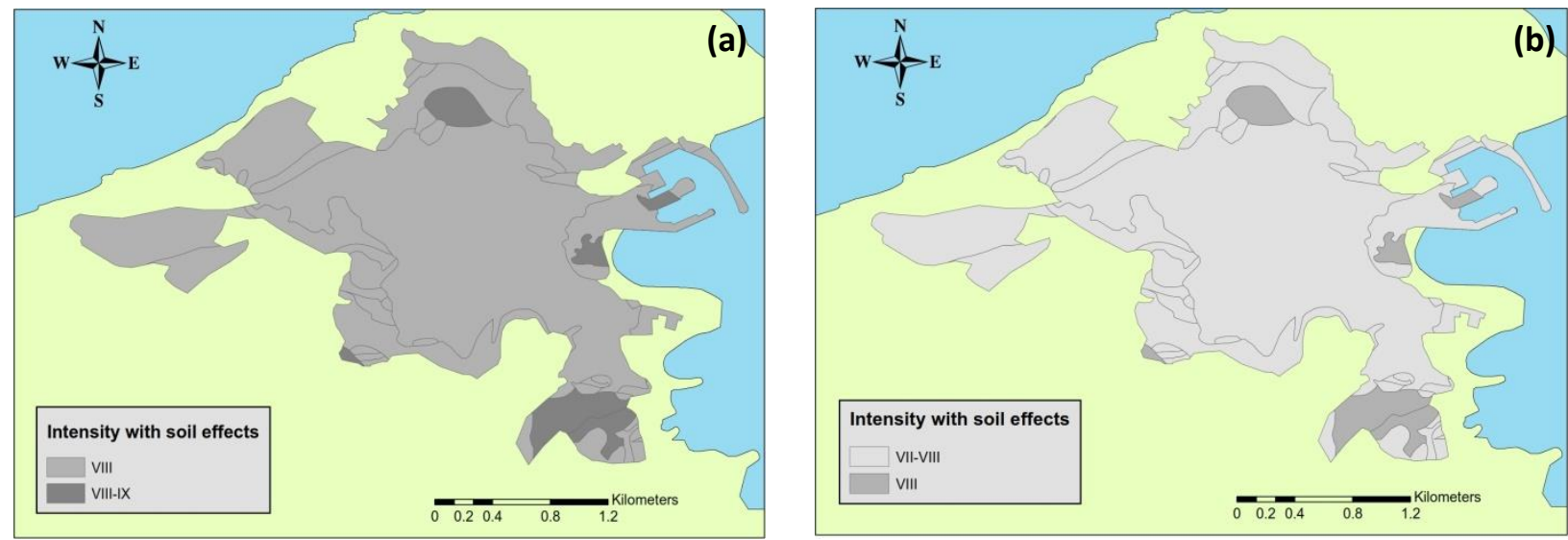

Fig. 7 a Deterministic intensity map with soil effects for the city of Al Hoceima. b Probabilistic intensity map for a return period of 475 years including soil effects for the city of Al Hoceima

\section{Seismic risk assessment using the Vulnerability Index Method}

The Vulnerability Index Method (VIM), as proposed in the Risk-UE project (Giovinazzi and Lagomarsino 2002) is used in this work. This method was formerly proposed by Benedetti and Petrini (1984) and is based on the European Macroseismic Scale (Grünthal 1998). It has advantages over similar statistical methods (ATC-13 1985, Grünthal 1998), because it focuses on the differences among constructions that have the same structural build. The most important parameters affecting the seismic strength of the buildings are given weighted coefficients quantifying their relative importance. The method requires 
the seismic action to be interpreted in terms of macroseismic intensity and the structural resistance of the buildings as a vulnerability index taking values going from 0 (least vulnerable building) to 1 (most vulnerable building).

This method provides a typological classification system (Giovinazzi and Lagomarsino 2002) in order to group structures with a similar seismic performance $\mathrm{V}_{\mathrm{I}}$ class (Table 2), then adds behaviour modifiers to evaluate a final vulnerability index of

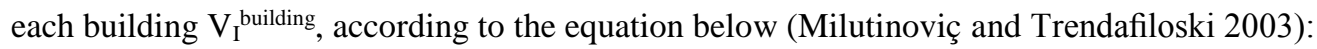

$$
V_{I}^{\text {building }}=V_{I}^{\text {class }}+\Delta M_{R}+\sum_{j=1}^{n} V m_{j}
$$

where $V_{I}^{\text {class }}$ is the vulnerability index corresponding to the class of the building, $\Delta M_{R}$ is a regional modifier which takes into account the characteristics of the region or building period, and lastly, $V m_{j}$ are behaviour modifiers that include other aspects that affect the seismic performance of the building.

In the case of Al Hoceima, the regional modifier was taken equal to zero. The adaptation of the VIM was sequenced around defining the code level according to the main construction periods.

Table 2 Vulnerability index values for several cases of the building typology matrix, BTM, proposed by Risk-UE (Milutinoviç and Trendafiloski 2003)

\begin{tabular}{|l|l|r|r|r|r|r|}
\hline \multirow{2}{*}{ Typology } & Description & \multicolumn{5}{|c|}{ V $_{\text {I representative values }}$} \\
\cline { 3 - 7 } & & $V_{I, B T M}^{\min }$ & $V_{I, B T M}^{-}$ & $V_{I, B T M}^{*}$ & $V_{I, B T M}^{+}$ & $V_{I, B T M}^{\max }$ \\
\hline M1.1 & Rubble stone, fieldstone & 0.62 & 0.81 & 0.873 & 0.98 & 1.02 \\
\hline M1.2 & Simple stone & 0.46 & 0.65 & 0.74 & 0.83 & 1.02 \\
\hline RC1 & Concrete Moment Frames & -0.02 & 0.047 & 0.442 & 0.8 & 1.02 \\
\hline RC2 & Concrete shear walls & -0.02 & 0.047 & 0.386 & 0.67 & 0.86 \\
\hline RC3.1 & Regularly infilled walls & -0.02 & 0.007 & 0.402 & 0.76 & 0.98 \\
\hline RC3.2 & Irregular frames & 0.06 & 0.127 & 0.522 & 0.88 & 1.02 \\
\hline S1 & Steel Moment Frames & -0.02 & 0.467 & 0.363 & 0.64 & 0.86 \\
\hline S2 & Steel braced Frames & -0.02 & 0.467 & 0.287 & 0.48 & 0.7 \\
\hline W & Wood structures & 0.14 & 0.207 & 0.447 & 0.64 & 0.86 \\
\hline
\end{tabular}

Two kinds of behavior modifiers are defined; building modifiers and location modifiers (Table 3). The building modifiers take into account the characteristics of the building isolated from its vicinity, like the state of preservation, number of floors, horizontal and vertical irregularities. Whereas the location modifiers study the building in its environment; for instance, aggregate buildings and soil morphology (Milutinoviç and Trendafiloski 2003).

Concerning damage, the Risk-UE VIM version uses five non-null damage states; Slight, Moderate, Substantial to Heavy, Very Heavy and Destruction (Grünthal 1998). A mean damage grade $\mu_{D}$ is introduced to characterize the expected damage for a building, for a given vulnerability $\left(V_{I}\right)$ and intensity $(I)$ by the following equation:

$$
\mu_{D}=2.5\left[1+\tanh \left(\frac{I+6.25 V_{I}-13,1}{\phi}\right)\right]
$$

where $\phi$ is the ductility index, which is evaluated taking into account the building typology and its constructive features (Lagomarsino and Giovinazzi 2006). For residential buildings, it takes a value of 2.3 (Lantada et al. 2010). 
Table 3 Scores for the vulnerability factors $V_{m}$ for reinforced concrete buildings (Milutinoviç and Trendafiloski 2003)

\begin{tabular}{|c|c|c|c|c|}
\hline \multirow{2}{*}{ Vulnerability Factors } & \multicolumn{3}{c|}{ Code Level } \\
\cline { 2 - 4 } & Pre or Low & Medium & High \\
\hline \multicolumn{2}{|c|}{ Code Level } & +0.16 & 0 & -0.16 \\
\hline \multicolumn{2}{|c|}{ Bad Maintenance } & +0.04 & +0.02 & 0 \\
\hline \multirow{3}{*}{ Number of floors } & Low (1,2) & -0.04 & -0.04 & -0.04 \\
\cline { 2 - 5 } & Medium (3,4,5) & 0 & 0 & 0 \\
\cline { 2 - 5 } & High (6 or more) & +0.08 & +0.06 & +0.04 \\
\hline \multirow{2}{*}{ Plan Irregularity } & Shape & +0.04 & +0.02 & 0 \\
\cline { 2 - 5 } & Torsion & +0.02 & +0.01 & 0 \\
\hline \multicolumn{2}{|c|}{ Vertical Irregularity } & +0.04 & +0.02 & 0 \\
\hline \multicolumn{2}{|c|}{ Short-column } & +0.02 & +0.01 & 0 \\
\hline \multicolumn{2}{|c|}{ Bow windows } & +0.04 & +0.02 & 0 \\
\hline Aggregate buildings (insufficient aseismic joint) & +0.04 & 0 & 0 \\
\hline \multirow{2}{*}{ Foundation } & Beams & -0.04 & 0 & 0 \\
\cline { 2 - 5 } & Connected beams & 0 & 0 & 0 \\
\cline { 2 - 5 } & Isolated footing & +0.04 & 0 & 0 \\
\cline { 2 - 5 } & Slope & +0.02 & +0.02 & +0.02 \\
\hline \multirow{2}{*}{ Soil Morphology } & Cliff & +0.04 & +0.04 & +0.04 \\
\hline
\end{tabular}

197

A weighted mean damage index, $D S_{m}$, can be calculated by using the following equation (Milutinoviç and Trendafiloski 2003):

$$
D S_{m}=\sum_{k=0}^{5} k P\left[D S_{k}\right]
$$

where the integer $k$ takes values from 0 to 5 for the damage states $k$ considered in the analysis and $P\left[D S_{k}\right]$ represents the corresponding probabilities of occurrence for the damage state $k$.

The damage distribution is calculated using the beta distribution.

Probability density function:

$$
p_{\beta}=\frac{\Gamma(t)}{\Gamma(r) \Gamma(t-r)} \frac{(x-a)^{r-1}(b-x)^{t-r-1}}{(b-a)^{t-1}} \quad a \leq x \leq b
$$

Cumulative Density Function:

$$
P_{\beta}(x)=\int_{a}^{x} p_{\beta}(\varepsilon) d \varepsilon
$$

Where $\quad a=0 ; \quad b=6 ; \quad t=8 ; \quad r=t\left(0.007 \mu_{D}^{3}-0.052 \mu_{D}^{2}+0.2875 \mu_{D}\right)$

The discrete beta density probability function is calculated from the probabilities associated with damage grades $\mathrm{k}$ and $\mathrm{k}+1$ ( $\mathrm{k}$ $=0,1,2,3,4,5)$, as follows

$$
p_{k}=P_{\beta}(k+1)-P_{\beta}(k)
$$

The fragility curve defining the probability of reaching or exceeding certain damage grade are obtained directly from the cumulative probability beta distribution as follows: 


$$
P\left(D \geq D_{k}\right)=1-P_{\beta}(k)
$$

It can be considered that $D S_{m}$ is close to the most likely damage state of the structure. This damage index is equivalent to the mean damage grade, $\mu_{D}$, and it is useful for mapping and analyzing damage distributions by using a single parameter.

\section{Seismic vulnerability of the city of Al Hoceima}

All the available data have been collected and integrated into a spreadsheet program, then introduced in a geographic information system, which allowed performing a building analysis. Display of results has been compiled using the previously mentioned subdivision of the urban area (Fig. 3), in order to allow clearer and more coherent results.

The majority of the buildings in the city of Al Hoceima are constructed with reinforced concrete, since the city is newly established. The residential buildings are, in most cases, moment frame constructions with two to three floors and have a ground surface ranging from $100 \mathrm{~m}^{2}$ to $150 \mathrm{~m}^{2}$. Three main building typologies are distinguished, all in reinforced concrete: structures with reinforced concrete moment frame, regular reinforced concrete structure with masonry infill walls and irregular moment frame structures. These typologies correlate respectively with RC1, RC3.1 and RC3.2 in the building typology matrix proposed by Lungu et al. 2001 (Table 2).

The results following the buildings inspection (Table 4) show that each building class has a predominant code level. This is related to the changes in construction habits and laws in each main period (before 1960, between 1961 and 1994, after 1995).

Table 4 distribution of building typologies depending on Code Level for the studied buildings

\begin{tabular}{|l|l|ccc|}
\hline Code Level & Number of Buildings (\%) & Low Code & Medium Code & High Code \\
\hline RC1 & $544(50 \%)$ & $9 \%$ & $73 \%$ & $18 \%$ \\
\hline RC3.1 & $224(20 \%)$ & $0 \%$ & $15 \%$ & $85 \%$ \\
\hline RC3.2 & $334(30 \%)$ & $68 \%$ & $29 \%$ & $3 \%$ \\
\hline
\end{tabular}

The VIM was favored over vulnerability curve methods like HAZUS (1999) and LM2 (Milutinoviç and Trendafiloski 2003), because it focuses on the differences among constructions that belong to the same building type. While a vulnerability curve represents one class of building with a code level, it doesn't take into account the different behavior modifiers related to the building and its location (Table 3). Particularly, in the case of Al Hoceima, vulnerability factors have a significant presence (Fig. 8). In order to showcase the importance of modifiers, we compared the vulnerability index taking into account only the class and code level $\left(\mathrm{V}_{\mathrm{LC}}, \mathrm{V}_{\mathrm{MC}}\right.$, and $\left.\mathrm{V}_{\mathrm{HC}}\right)$, with the vulnerability indices of the studied buildings (Fig. 9). As can be seen, the difference of values is significant, especially in Low Code, where increments of behavior modifiers become more punishing.

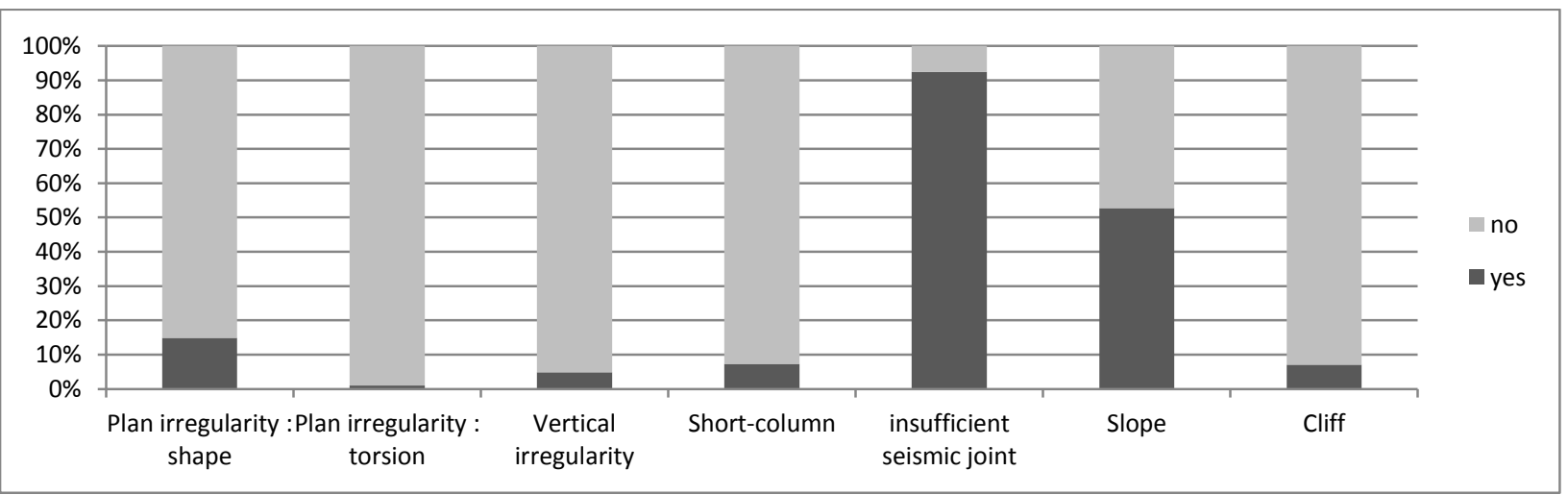

Fig. 8 Distribution of vulnerability factors for the studied building in Al Hoceima 

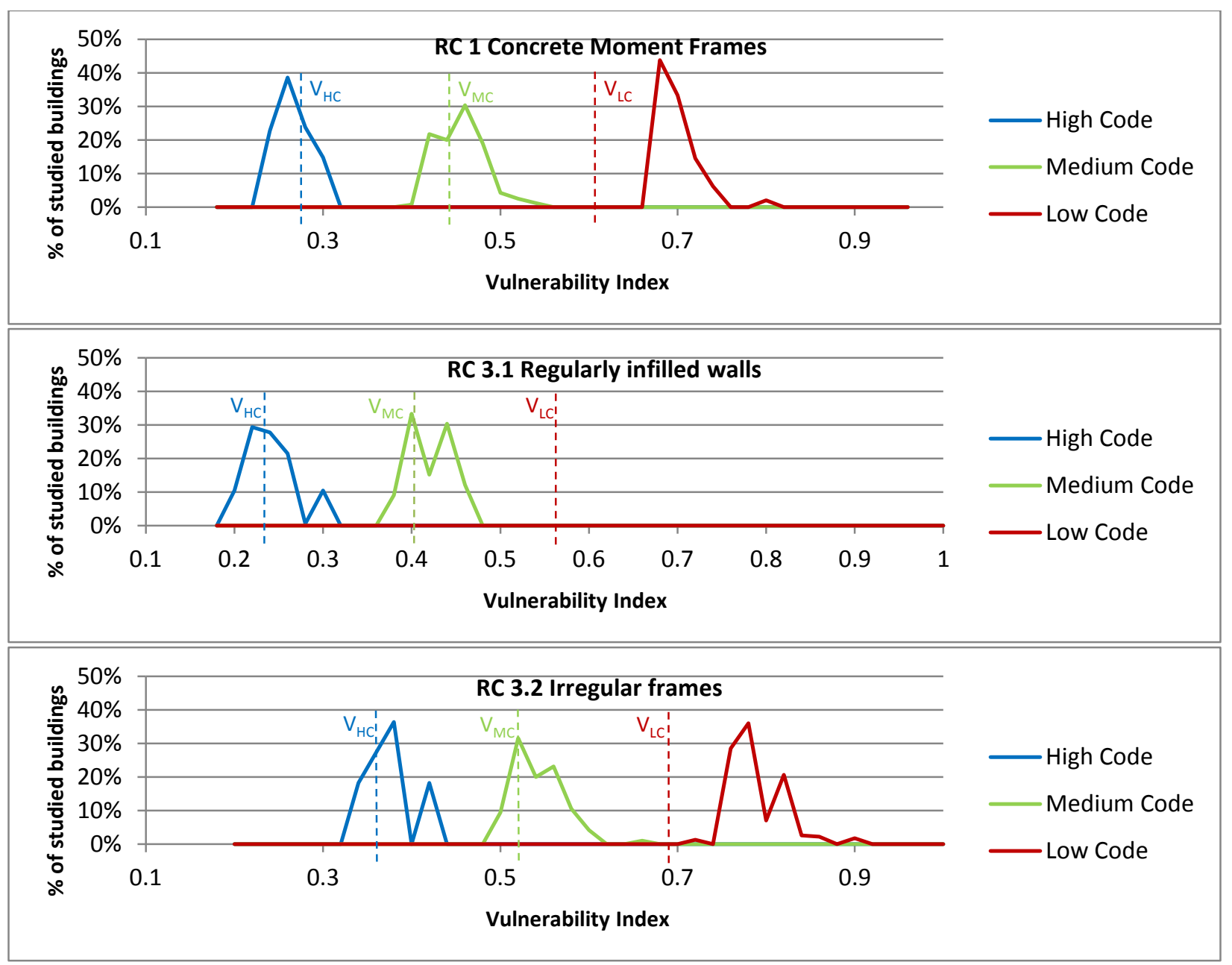

Fig. 9 Distribution of the total vulnerability index of the studied buildings in Al Hoceima, in terms of building class and code level

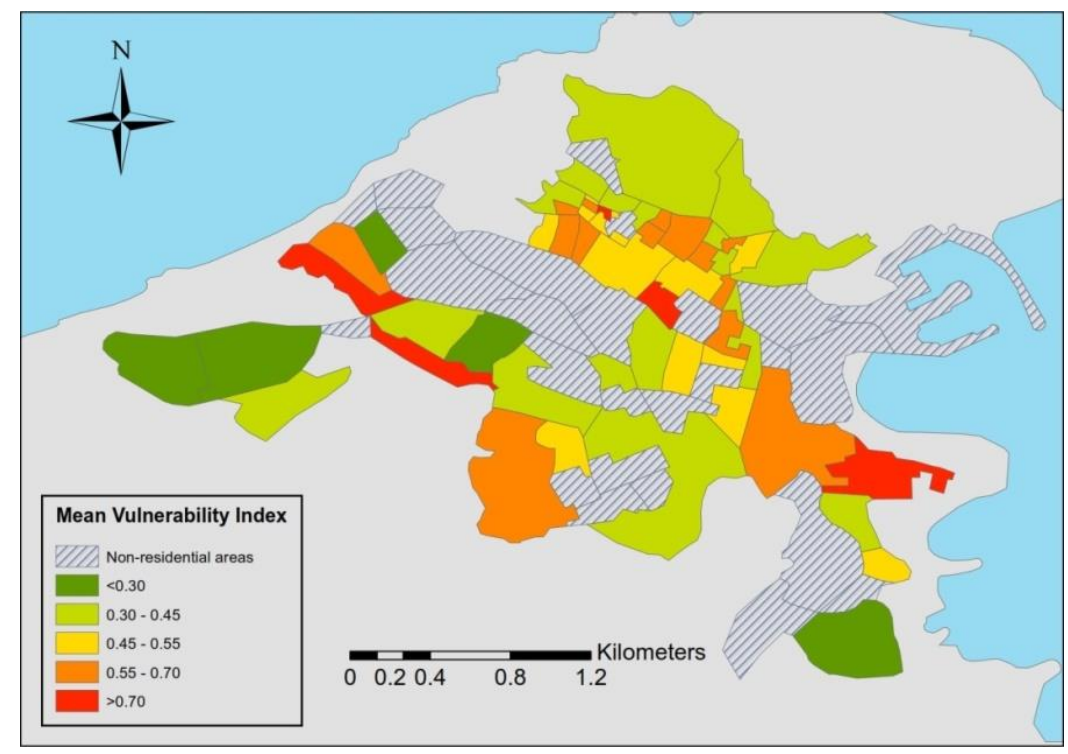

Fig. 10 Mean vulnerability index for the residential buildings in the city of Al Hoceima 
The vulnerability index takes values ranging from 0.2 to 0.9 for the studied buildings, with a mean value of 0.49 . Values of $\mathrm{V}_{\mathrm{I}}$ for the different sections in the city are shown in Figure 10. As it could have been predicted, the southern neibourhoods in Mirador Bas and Mirador Haut are by far the most vulnerable areas in Al Hoceima, with mean vulnerability indices of 0.81 and 0.83 respectively. This is primarily due to the poor choice of terrain and the low quality of construction in these regions in particular.

\section{Seismic risk scenarios for the city of Al Hoceima}

\subsection{Physic direct damage}

Concerning the mean damage grade, it almost follows the distribution of the vulnerability index in Figure 10, since soil effect is present in small areas of the city (equivalent of $7 \%$ of the total surface). Figure 11 shows values of damage according to both deterministic and probabilistic scenarios, no large differences are noticed between both. The values of physical damage are ranging from 0.17 to 3.07 for the deterministic scenario and 0.11 to 2.54 for the probabilistic one, with mean values of 0.96 and 0.7 respectively. This corresponds in both cases to a slight damage state according to Table 5.

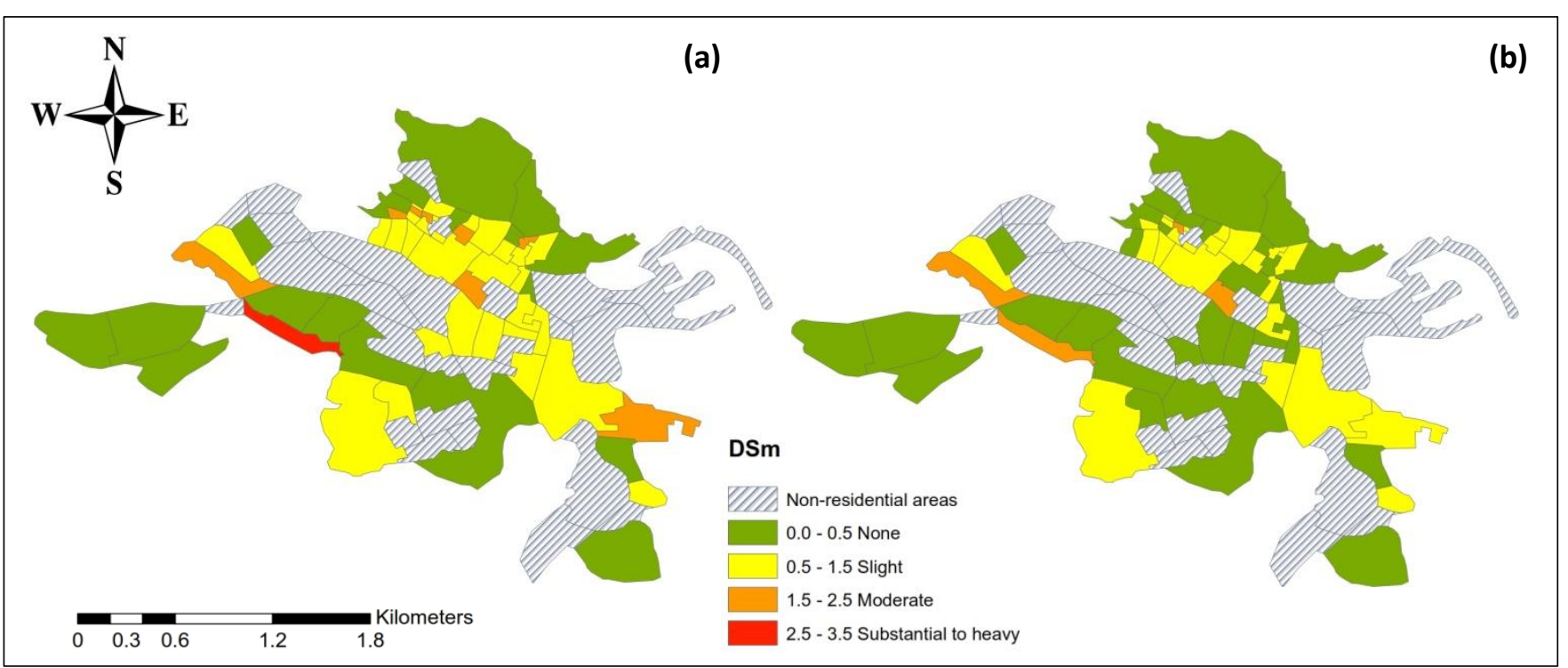

Fig. 11 Mean damage grade for each section for, a The deterministic seismic hazard scenario. $\mathbf{b}$ The probabilistic seismic hazard scenario

Table 5 Mean damage index values and damage states

\begin{tabular}{|l|l|}
\hline Mean damage index intervals $\left.\mathbf{( D S}_{\mathbf{m}}\right)$ & Most probable damage state \\
\hline $0.0-0.5$ & None \\
\hline $0.5-1.5$ & Slight \\
\hline $1.5-2.5$ & Moderate \\
\hline $2.5-3.5$ & Substantial to heavy \\
\hline $3.5-4.5$ & Very heavy \\
\hline $4.5-5.0$ & Destruction \\
\hline
\end{tabular}

Also in this case, the highest damage is expected in the southern neibourhoods of Mirador Bas and Mirador Haut districts, with mean values of 2.6 and 2.44 for the deterministic scenario and 2.06 and 1.91 for the probabilistic one. These values correspond to a Moderate damage expected in these regions, except the physical damage in the case of Mirador Bas 
according to the deterministic scenario, which is Substantial to heavy. The damage distribution shows that there is possibility of very heavy damage on buildings in some districts (Fig. 12, Fig 13), especially in Mirador Bas, Mirador Haut and Morobikho, which are the most affected regions in the city.

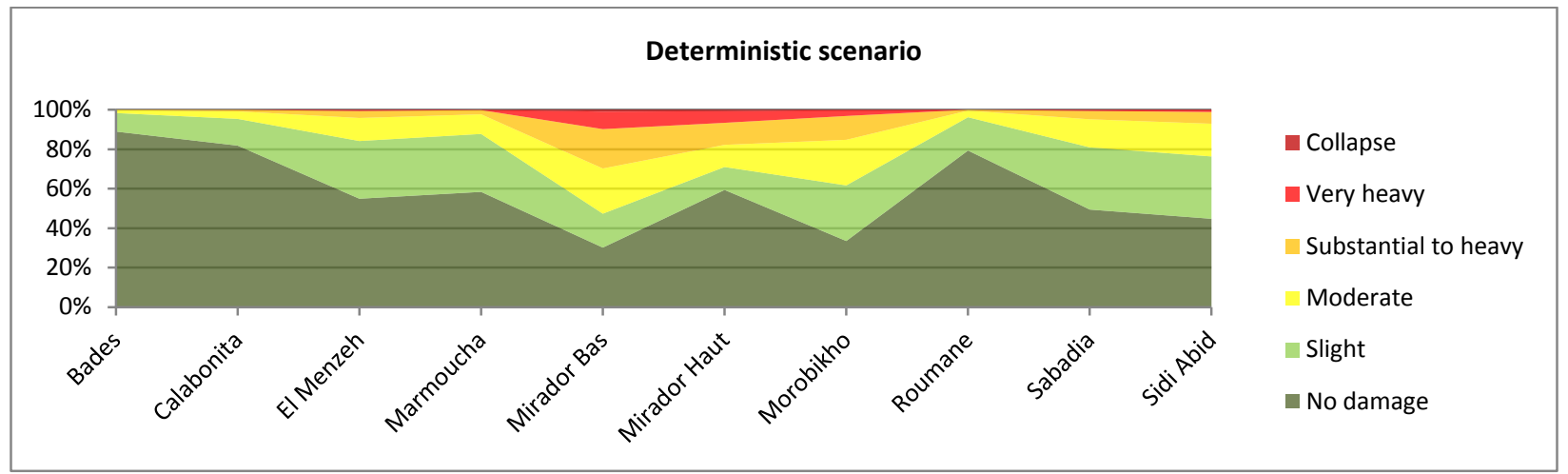

Fig. 12 Probability of damage states in the residential districts of Al Hoceima for the deterministic scenario

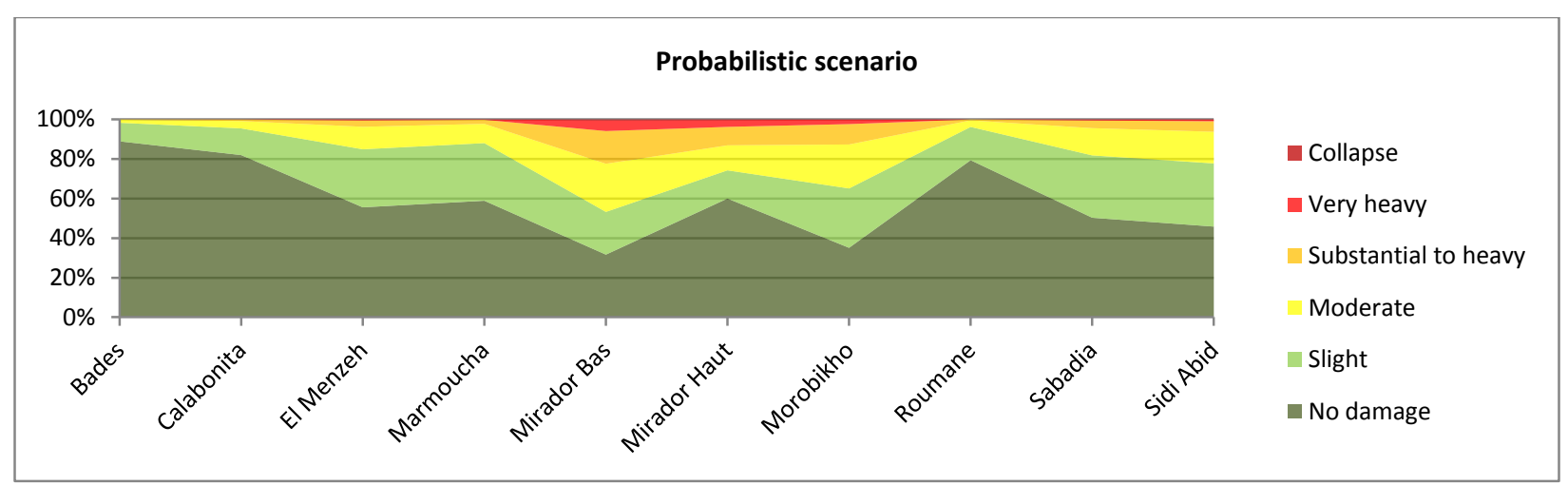

Fig. 13 Probability of damage states in the residential districts of Al Hoceima for the probabilistic scenario

\subsection{Damage to population}

According to Coburn and Spence (2002), deaths and injuries may occur if a building has collapsed, which isn't the case in the city of Al Hoceima based on this study. Therefore, there are no casualties expected for both scenarios. However, the number of people that must be relocated due to uninhabitable buildings is an important part in disaster management, and should be focused on. The methodology that has been applied is based on HAZUS (1999), it considers the 100\% of residential units located in buildings that are in the very heavy and destruction damage state and the $90 \%$ that are in substantial to heavy damaged structures to be uninhabitable.

The total number of uninhabitable residential units due to structural damage is computed by the following relationship:

with $U_{M F}$ being the total number of multi-family residential units, $\% H_{M F}, \% V H_{M F}$ and $\% D_{M F}$ the damage state probability for substantial to heavy, very heavy and destruction structural damage state, respectively, in the multi-family residential occupancy class.

$$
\begin{gathered}
\% M F=0.9 \times \% H_{M F}+1.0 \times \% V H_{M F}+1.0 \times \% D_{M F} \\
U N U_{S D}=U_{M F} \times \% M F
\end{gathered}
$$




$$
P_{U N U}=P_{h} \times U N U_{S D}
$$

where $P_{h}$ is the number of persons who are assumed to live in each household of the building. According to the RGPH 2004, an average of 5 persons per household is estimated for the city.

The numbers of homeless people that are expected in both the deterministic and probabilistic scenarios are displayed in Figure 14. The total number of homeless people expected in both scenarios is 1991 and 117 respectively. The big difference between the two results is due to the fact that the damage exceeded the "Substantial to heavy" limit in the deterministic scenario. It is also worth mentioning that $76 \%$ of the homeless are located in Mirador Bas and Mirador Haut areas for the deterministic scenario and $95 \%$ of the homeless for the probabilistic one, while the two latter districts represent only $8 \%$ of the total area of Al Hoceima.

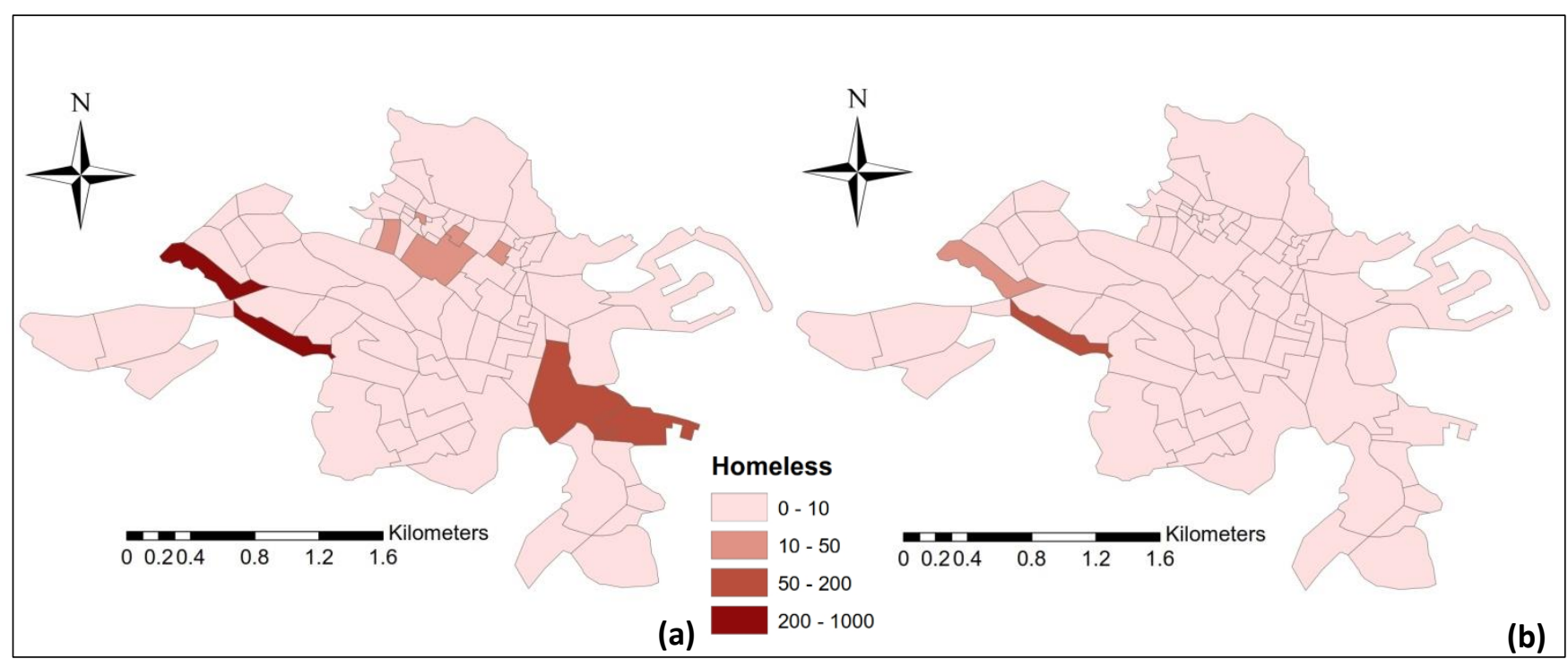

Fig. 14 Number of homeless people for each section for, a The deterministic seismic hazard scenario. b The probabilistic seismic hazard scenario

\subsection{Economic Cost}

The economic cost is estimated as the present restoration cost of the damaged buildings. This value is estimated by reconstructing the building with reinforced concrete without including the land cost. The absolute economic cost $\left(S_{\text {Cost }}\right)$ in thousands of Euros is given by the following equation (HAZUS 1999):

$$
S_{\text {Cost }}=\sum_{k=2}^{5} C S(k)=V_{C} \sum_{K=2}^{5} \sum_{J=1}^{N e}\left[\operatorname{Area}(j) \cdot P_{S}(k, j) \cdot R C(k, j)\right]
$$

where $\mathrm{S}_{\text {Cost }}$ is the sum of the $C S(k)$ repair costs due to the damage state $k$ (damage state 1 none is not considered since there is no induced cost); $V_{C}$ is the cost per unit area $\left(\mathrm{m}^{2}\right)$; Area is the building area; $P S(k, j)$ is the probability for the building $j$ to be in the damage state $k$ and $R C(k, j)$ is the repair value due to the damage state $\mathrm{k}$ for the building $j ; R C(k, j)$ is given as a percentage of the reposition cost per square meter according to Table 6. AUTh loss indices have been used in this study since damages in case of Slight and Moderate are easily repaired and don't require great expenses.

Vc includes the construction cost of the building and the cost of furniture, and it's been calculated using the following equation: 


$$
\begin{gathered}
V_{C}=G L_{C}+(n-1) \cdot F_{C}+n \cdot M_{C} \\
F_{C}=0.5 \times G L_{C}
\end{gathered}
$$

Where $G L_{C}$ is the construction cost of the ground level of a reinforced concrete building, $F_{C}$ is the construction cost of a floor other than the ground level, $M_{C}$ is the cost of residential building contents and $n$ is the number of floors. A reasonable value of $G L_{C}$ for a residential building is $150 € / \mathrm{m}^{2}$ according to the Moroccan construction market, while $M_{C}$ is given a value of 28 $€ / \mathrm{m}^{2}$. Figure 15 shows the economic cost in thousands of Euros for each section in the city, caused by the deterministic and probabilistic earthquake hazard scenarios. The total economic cost for the city is 5.6 Millions of Euros in case of the deterministic scenario, and 5.1 Millions of Euros in case of the probabilistic scenario.

Table 6 Loss Indices for reinforced concrete buildings

\begin{tabular}{|l|l|l|c|}
\hline $\begin{array}{c}\text { Damage } \\
\text { Grade }\end{array}$ & \multicolumn{1}{|c|}{$\begin{array}{c}\text { Damage Grade } \\
\text { Label (VIM) }\end{array}$} & \multicolumn{1}{|c|}{ Description } & $\begin{array}{c}\text { Loss Indices } \\
\text { Aristotle University of Thessaloniki } \\
\text { (AUTh) }\end{array}$ \\
\hline 0 & None & No damage & 0.0 \\
\hline 1 & Slight & Negligible to slight damage & $0.0-0.05$ \\
\hline 3 & Moderate & Slight structural, moderate nonstructural & $0.05-0.2$ \\
\hline 4 & Substantial to heavy & Moderate structural, heavy nonstructural & $0.2-0.5$ \\
\hline 5 & Very heavy & Heavy structural, very heavy nonstructural & $0.5-1.0$ \\
\hline
\end{tabular}

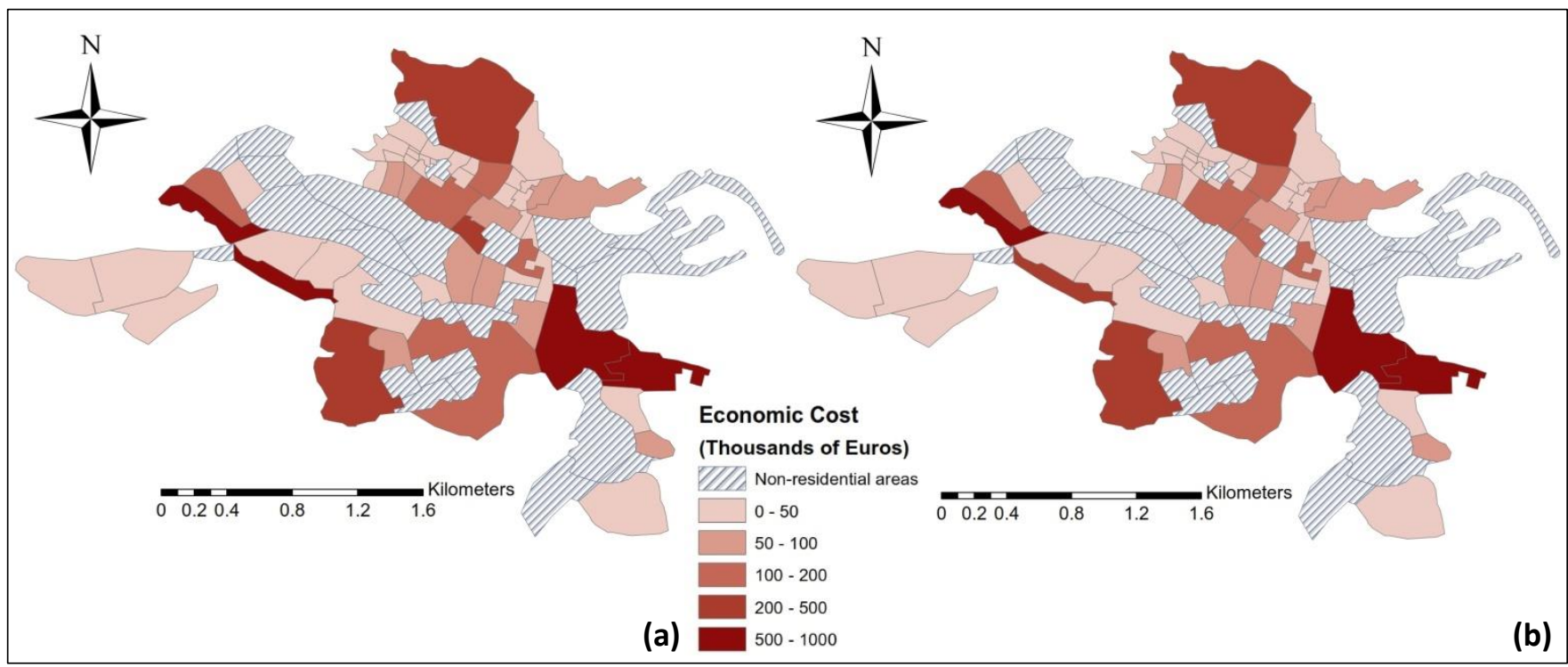

Fig. 15 Distribution of economic cost for each section for, a The deterministic seismic hazard scenario. b The probabilistic seismic hazard scenario

\section{Discussion and conclusions}

The seismic risk assessment has been performed for the city of Al Hoceima using the VIM version, as proposed in the framework of the Risk-UE project. The seismic hazard assessment and the seismic vulnerability assessment allowed estimating the distribution of the expected damage caused by the considered seismic scenarios. The data gathered for this study allowed an acceptable assessment of the vulnerability indices of the buildings. However, the study might benefit from more data collection, particularly around areas that haven't been well studied as is previously shown in Figure 3 (b). Seismic hazard has been assessed by means of macroseismic intensity, considering both the deterministic and probabilistic scenarios, 
including soil effects. The intensity ranges from VIII to VIII-IX for the deterministic scenario, while it varies from VII-VIII to VIII for the probabilistic scenario.

The risk assessment in the city has been performed, using the seismic hazard scenarios. The results show that for a city that is often threatened by earthquakes, the damage expected is slight, since Al Hoceima is not exposed to soils effects and most of the buildings (especially the ones built before 2004) have low vulnerability indices. However, the highest damage (substantial to heavy) is expected in newly established neighborhoods, which is uncommon. As a matter of fact, if the 2004 earthquake were to strike the city in 2016, the damage would probably be more important. The city doesn't have any adequate lands for construction left; therefore local people are building their homes in inappropriate spots threatened mostly by slopes, with minimal consideration for the seismic standards of construction.

This method has proven to be a simple statistical tool for evaluating the vulnerability of residential buildings and assessing seismic risk when limited information is available. However, validation of results is crucial, and it is a major issue for earthquake scenarios because of the great uncertainties involved. The best validation test is the occurrence of the simulated earthquake scenario; this would prove the similarities between the simulation and the observed damage, and validate both the method used and the quality of the data.

According to damage reports of the 2004 earthquake (Faradi 2004; Corella 2004; Poujol et al. 2004; Goula and Gonzalez 2004) Al Hoceima was not affected by the earthquake and the majority of these buildings have withstood the shocks. The number of buildings affected by the earthquake remains insignificant at the urban area of Al Hoceima. However, In Al Manzah district, there were some cracks in partitions and openings in corner buildings particularly those built on sloping ground (Faradi 2004). In this case, the simulated earthquake scenarios occur twelve years after the 2004 earthquake. If the new expansions and neighborhoods (western and south-eastern part of the city) that have been constructed after 2004 are excluded from the scenarios; the results would concur with the real damage that occurred in the aftermath of the 2004 earthquake. Moreover, seismic vulnerability results based on this study concur with past studies in the city, using the EMS98 (Louhibi et al. 2013). For these reasons, the risk scenarios developed in this paper are considered to be reliable.

The results of this study represent a potential guide for earthquake protection and risk management in the city, as well as a powerful tool in urban development. It is worth noting that the original results described in this paper, together with the complete and detailed technical information concerning the expected damage, loss to property and damage to population, will be delivered to the civil protection services of the municipality of Al Hoceima who will be using them for updating the emergency plans of the city.

\section{References}

Akoglu AM, Cakir Z, Meghraoui M, Belabbes S, El Alami SO, Ergintav S, Akyüz HS (2006) The 1994-2004 Al Hoceima (Morocco) earthquake sequence: Conjugate fault ruptures deduced from InSAR. Earth and Planetary Science Letters Volume 252, Issues 3-4, 15 December 2006, Pages 467-480 doi:10.1016/j.eps1.2006.10.010

d'Acremont E, Gutscher M-A, Rabaute A, Mercier de Lépinay B, Lafosse M, Poort J, Ammar A, Tahayt A, Le Roy P, Smit J, Do Couto D, Cancouët R, Prunier C, Ercilla G, Gorini C (2014) High-resolution imagery of active faulting offshore Al Hoceima, Northern Morocco. Tectonophysics Volume 632, 29 September 2014, Pages 160-166, http://dx.doi.org/10.1016/j.tecto.2014.06.008

Ait Brahim L, Tadili B, Nakhcha C, Mouayn I, Ramdani M, Limouri M, El Qadi A, Sossey Alaoui F, Benhalima M, (2004) Using active faults and seismicity for the strong motion modeling in the eastern Rif (northern Morocco). Pure Appl Geophys 161 (2004) 1081-1091 0033 - 4553/04/061081 - 11 DOI 10.1007/s00024-003-2487-9

ATC-13 (1985) Earthquake damage evaluation data for California, ATC-13. Applied Technology Council, Redwook City

BAEL 91 (1992) Règles techniques de conception et de calcul des ouvrages et constructions en béton armé suivant la méthode des états-limites. Décret n092-72 du 16 janvier 1992. 
Benedetti D, Petrini V (1984) Sulla vulnerabilitá sismica di edifici in muratura: proposte di un metodo di valutazione. L'industria delle Construzioni 149:66-78

Bezzeghoud M, Buforn E (1999) Source parameters of the 1992 Melilla (Spain,Mw = 4.8), 1994 Al Hoceima (Morocco Mw $=5.8$ ) and Mascara (Algeria, $\mathrm{Mw}=5.7$ ) earthquakes and seismotectonic implications. Bull. Seismol. Soc. Am. 89,359372

Casado CL, Henares J, Badal J, Peláez JA (2014) Multifractal images of the seismicity in the Ibero-Maghrebian region (westernmost boundary between the Eurasian and African plates). Tectonophysics 627 (2014) 82-97

Cherkaoui T, Hatzfeld D, Jebli H, Medina F, Caillot V (1990) Etude microsismique dela région d'Al Hoceima. Bull. Inst. Sci. Rabat 4, 25-34

Cherkaoui T, El Hassani A (2012) Seismicity and Seismic Hazard in Morocco 1901-2010. Bulletin de l'Institut Scientifique, Rabat, section Sciences de la Terre, 2012, n 34, p. 45-55

Choubert G, Faure-Muret A (1984) Carte géologique du Rif : Al Hoceima - Echelle 1/50 000. ํㅜ 302

Coburn A, Spence R (2002) Earthquake protection, 2nd edn. Wiley, Chichester

Corella PM (2004) Al-Hoceima Earthquake. Field Report,51p.

El Alami SO, Tadili BA, Cherkaoui TE, Medina F, Ramdani M, Ait Brahim L, Har-nafi M (1998) The Al Hoceima earthquake of May 26, 1994 and its aftershocks:a seismotectonic study. Ann. Geofisic. 41, 519-537

Faccioli E (2006) Seismic hazard assessment for derivation of earthquake scenarios in Risk-UE. Bull Earthq Eng 4:341-364

Faradi (2004) Seisme d'Al Hoceima du 24-2-2004 Constat Technique, p 3

Giovinazzi S, Lagomarsino S (2002) Wp04: guidelines for the implementation of the level I methodology for the vulnerability assessment of current buildings. RISK-UE project: an advanced approach to earthquake risk scenarios with applications to different European towns. Contract No.EVK4-CT-2000-00014, Genoa

Goula X, Gonzalez M (2004) Visite technique à la zone endommagé par le séisme d'Al-hoceima du 24 février 2004. Generalitat de Catalunya. Institut Cartogràfic de Catalunya, ICC-GS-192/2004 (fr)

Grünthal G (1998) European macroseismic scale 1998. Centre Européen de Géodynamique et de Séismologie, Luxemburg HAZUS (1999) Earthquake loss estimation methodology technical manual, prepared by the National Institute of Building Sciences for Federal Emergency Management Agency (FEMA), Washington, D

Jabour N, Kasmi M, Menzhi M, Birouk A, Hni L, Hahou Y, Timoulali Y, Bedrane S, (2004). The February 24th, 2004 Al Hoceima earthquake, Newsletter of European-Mediterranean Seismological Centre, № 21, ISSN: 1607-1980.

Lagomarsino S, Giovinazzi S (2006) Macroseismic and mechanical models for the vulnerability and damage assessment of current buildings. Bull Earthq Eng 4:415-443

Lantada N, Irizarry J, Barbat AH, Goula X, Roca A, Susagna T, Pujades LG (2010) Seismic hazard and risk scenarios for Barcelona, Spain, using the Risk-UE vulnerability index method. Bull Earthquake Eng, DOI 10.1007/s10518-009-9148Z

Louhibi S, Chourak M, El Kihel E, El Hammoumi A, Douiri A (2013) Evaluation of the Seismic Vulnerability of Buildings in Al Hoceima (Morocco). International Journal of Earth Sciences and Engineering. December2013, P.P.1505-1511. ISSN 0974-5904, Volume 06, No. 06(01)

Lungu D, Aldea A, Arion A, Vacareanu R, Petrescu F, Cornea T (2001) WP1 report: European distinctive features, inventory database and typology. RISK-UE project: an advanced approach to earthquake risk scenarios with applications to different European towns. Contract No. EVK4-CT-2000-00014

Milutinoviç ZV, Trendafiloski GS (2003) WP04: vulnerability of current buildings handbook. RISK-UE project: an advanced approach to earthquake risk scenarios with applications to different European towns. Contract No. EVK4-CT-200000014, Institute of Earthquake Engineering and Engineering Seismology (IZIIS), Skopje

Mourabit T, Abou Elenean KM, Ayadi A, Benouar D, Ben Suleman A, Bezzeghoud M, Cheddadi A, Chourak M, ElGabry MN, Harbi A, Hfaiedh M, Hussein HM, Kacem J, Ksentini A, Jabour N, Magrin A, Maouche S, Meghraoui M, Ousadou F, Panza GF, Peresan A, Romdhane N, Vaccari F, Zuccolo E (2013) Neo-deterministic seismic hazard assessment in North Africa. J Seismol DOI 10.1007/s10950-013-9375-2

Mouroux P, Bertrand M, Bour M, Brun BL, Depinois S, Masure P, Risk-UE Team (2004) The European Risk-UE project: an advanced approach to earthquake risk scenarios. In: Proceedings of the 13th world conference earthquake engineering, Vancouver (CD-ROM, Paper No. 3329) 
Pitilakis K, Alexoudi M, Argyroudis S, Anastasiadis A (2006) Seismic risk scenarios for an efficient seismic risk management: the case of Thessaloniki (Greece). Advances in Earthquake Engineering for Urban Risk Reduction. pp 229-244. DOI 10.1007/1-4020-4571-9_15

Poujol A, Ritz J-F, Tahayt A, Vernant P, Condomines M, Blard P-H, Billant J, Vacher L, Tibari B, Hni L, Koulali Idrissi A (2014) Active tectonics of the Northern Rif (Morocco) from geomorphic and geochronological data. Journal of Geodynamics Volume 77, July 2014, Pages 70-88, doi:10.1016/j.jog.2014.01.004

PS92 (1995) Règles PS applicables aux bâtiments. NF P 06-013 -DTU Règles PS 92, Décembre 1995.

RGPH 2004 (2004) Recensement général de la population et de l'habitat 2004. http://www.hcp.ma/Recensement-general-dela-population-et-de-1-habitat-2004_a633.html

RGPH 2014 (2014) Population légale des régions, provinces, préfectures du royaume d'après les résultats du RGPH 2014 (12 Régions).http://www.rgph2014.hcp.ma/Note-sur-les-premiers-resultats-du-Recensement-General-de-la-Population-etde-1-Habitat-2014_a369.html

RMSI (2012) Morocco natural hazards probabilistic analysis and national strategy development. Earthquake hazard report. Department of Economic and General Affairs, Kingdom of Morocco

R.P.S. 2000 (2002) Règlement de construction parasismique. Ministère de l'Aménagement du Territoire, de l'Urbanisme, de l'Habitat et de l'Environnement. Secrétariat d'Etat à l'Habitat

R.P.S. 2000, Version 2011 (2011) Règlement de construction parasismique. Ministère de l'Habitat, de l'Urbanisme et de l'Aménagement de l'Espace

Secanell R (1999) Avaluació de la perillositat sísmica a Catalunya: anàlisi de sensibilitat per a diferents models d'ocurrència i paràmetres sísmics, Ph.D. Thesis, University of Barcelona

Tahayt A, Feigl KL, Mourabit TL, Rigo A, Reilinger R, McClusky S, Fadil A, Dorbath L, Serroukh M, Gomez F, Ben Sari D, Berthier E (2009) The Al Hoceima (Morocco) earthquake of 24 February 2004, analysis and interpretation of data from ENVISAT ASAR and SPOT5 validated by ground-based observations. Remote Sensing of Environment 113 (2009) 306-316. doi:10.1016/j.rse.2008.09.015

USGS (2016) M6.3 - 50km NNE of Al Hoceima. Morocco.http://earthquake.usgs.gov/earthquakes/eventpage/us10004gy9\# general_region

Woerd JVD, Dorbath C, Ousadou F, Dorbath L, Delouis B, Jacques E, Tapponnier P, Hahou Y, Menzhi M, Frogneux M, Haessler H (2014) The Al Hoceima Mw 6.4 earthquake of 24 February 2004 and its aftershocks sequence. Journal of Geodynamics. Volume 77, July 2014, Pages 89-109. doi:10.1016/j.jog.2013.12.004 